\title{
BMJ Open Urinary incontinence and sedentary behaviour in nursing home residents in Osona, Catalonia: protocol for the OsoNaH project, a multicentre observational study
}

\author{
Pau Farrés-Godayol (D) ,' Javier Jerez-Roig (D) , ${ }^{1}$ Eduard Minobes-Molina (i) , \\ Meltem Yildirim (D) , ${ }^{1}$ Ester Goutan-Roura (D) , ${ }^{2}$ Laura Coll-Planas (D) , 1,3 \\ Anna Escribà-Salvans (D) ," Miriam Molas-Tuneu (i) , ${ }^{1}$ Pau Moreno-Martin, ${ }^{1}$ \\ Sandra Rierola-Fochs (D) , ${ }^{1}$ Sergi Rierola-Colomer, ${ }^{1}$ Montse Romero-Mas (D) , \\ Miriam Torres-Moreno (iD ,' Jordi Naudó-Molist (i) , ${ }^{4}$ \\ Dyego Leandro Bezerra de Souza (D) , ${ }^{1,5}$ Joanne Booth (D) , ${ }^{6}$ Dawn A Skelton (D) ,6 \\ Maria Giné-Garriga (D) ${ }^{7,8}$
}

To cite: Farrés-Godayol $P$, Jerez-Roig J, Minobes-Molina E, et al. Urinary incontinence and sedentary behaviour in nursing home residents in Osona, Catalonia: protocol for the OsoNaH project, a multicentre observational study. BMJ Open 2021;11:e041152. doi:10.1136/ bmjopen-2020-041152

- Prepublication history for this paper is available online. To view these files, please visit the journal online (http://dx.doi org/10.1136/bmjopen-2020041152).

PF-G and JJ-R contributed equally.

Received 04 June 2020 Revised 14 January 2021 Accepted 24 March 2021

Check for updates

(c) Author(s) (or their employer(s)) 2021. Re-use permitted under CC BY-NC. No commercial re-use. See rights and permissions. Published by BMJ.

For numbered affiliations see end of article.

Correspondence to Dr Eduard Minobes-Molina; eduard.minobes@uvic.cat

\section{ABSTRACT}

Introduction Several studies have shown that physical activity (PA) levels and sedentary behaviour (SB) are independent risk factors for many health-related issues. However, there is scarce evidence supporting the relationship between SB and urinary incontinence (UI) in community-dwelling older adults, and no information on any possible association in institutionalised older adults. Stage I of this project has the main objective of determining the prevalence of $\mathrm{Ul}$ and its associated factors in nursing home $(\mathrm{NH})$ residents, as well as analysing the association between UI (and its types) and SB. Stage II aims to investigate the incidence and predictive factors of functional and continence decline, falls, hospitalisations, mortality and the impact of the COVID-19 pandemic among $\mathrm{NH}$ residents.

Methods and analysis Stage $I$ is an observational, multicentre, cross-sectional study with mixed methodology that aims to explore the current status of several healthrelated outcomes in NH residents of Osona (Barcelona, Spain). The prevalence ratio will be used as an association measure and multivariate analysis will be undertaken using Poisson regression with robust variance. Stage II is a 2-year longitudinal study that aims to analyse functional and continence decline, incidence of falls, hospitalisations, mortality and the impact of the COVID-19 pandemic on these outcomes. A survival analysis using the actuarial method for functional decline and continence, evaluated every 6 months, and the Kaplan-Meier method for falls, hospitalisations and deaths, and Cox regression for multivariate analysis will be undertaken.

Ethics and dissemination The study received the following approvals: University of Vic - Central University of Catalonia Ethics and Research Committee (92/2019 and 109/2020), Clinical Research Ethics Committee of the Osona Foundation for Health Research and Education (FORES) (code 2020118/PR249). Study results will be

\section{Strengths and limitations of this study}

- The first study to focus on the association between urinary incontinence and sedentary behaviour (SB) in the older institutionalised population and the largest study analysing SB patterns in the older institutionalised population with a gold standard measure (activPAL3).

- Mixed methods study (quantitative and qualitative approach) considering a wide range of variables to assess health, based on the biopsychosocial model.

- An initial cohort first assessed before the pandemic (from January to March 2020) will be followed up to analyse the impact of COVID-19 in nursing home $(\mathrm{NH})$ residents.

- Limitations include participation of NH residents or legal guardians in research-based studies, cognitive impairment that may affect information on some independent variables that require the participant response and the potential increase in SB during the COVID-19 pandemic.

disseminated at conferences, meetings and through peerreviewed journals.

Trial registration number NCT04297904.

\section{INTRODUCTION}

Low birth rates and an increased life expectancy are transforming the age pyramid of the European Union (EU); probably the most important change will be the marked transition towards an aged society, a characteristic that is already evident in several EU member states. In 2017 , the $65+$ population had an increase of $0.3 \%$ compared with the 
previous year, and an increase of $2.4 \%$ compared with the previous 10 years, in fact people aged over 80 years old are increasing at a faster rate than any other age segment of the EU population. ${ }^{1}$ This increase is linked to a growing demand for long-term care, which represents a significant overload on public health resources. One in four older adults will spend a period of their life in a nursing home $(\mathrm{NH})$, and the need for such care will persist until their death. ${ }^{2}$ Older adults who live in an $\mathrm{NH}$ are the most frail of our society with high levels of functional limitations and physical dependence, ${ }^{34}$ and one-third of them have cognitive impairment. ${ }^{5}$

The prevalence of urinary incontinence (UI) in Spain is approximately $10 \%$ in women aged between 25 and 64 years old, and over $50 \%$ in those over 65 years old. ${ }^{6}$ In NHs, this proportion is around $50 \%$ and is frequently associated with cognitive impairment, physical inactivity and immobility syndrome, among other factors. ${ }^{7}$ In this context, we can find a type of UI described as 'functional' in that it is caused by an inability to move to the toilet independently, due to a physical, communicative or cognitive problem (eg, dementia). ${ }^{8}$ Most older adults mistakenly believe that incontinence is part of the normal ageing process and/or is an irresolvable problem. ${ }^{9}{ }^{10}$ However, UI is a geriatric syndrome that represents an indicator of frailty and quality of healthcare, as well as a risk factor for pressure ulcers, falls, fractures and even urinary sepsis or death. ${ }^{11-13}$

$\mathrm{NH}$ residents are the least physically active of all older adults and spend most of their awake time sedentary. ${ }^{15}$ Doing regular physical activity (PA) limits the development and progression of most prevalent chronic diseases. ${ }^{16}$ However, the time spent in sedentary behaviour (SB) by older adults has increased considerably in the last three decades ${ }^{17}$ and SB increases with age. ${ }^{18}$ SB has been gaining recognition as a risk factor for specific health conditions and reduced mobility, sometimes independent of PA levels. ${ }^{19}$ A typical day for a resident will consist in a sequence of periods of SB, light intensity PA (LPA) and moderate to vigorous intensity PA (MVPA). ${ }^{20}{ }^{21} \mathrm{NH}$ residents spend an average of $79 \%$ of their day sedentary, $20 \%$ in LPA and $1 \%$ in MVPA. ${ }^{22}$

There is a consensus among researchers that low levels of PA and prolonged patterns of SB could be direct risk factors for UI in older adults. ${ }^{23-26}$ A recent observational study on the association between SB and UI in communitydwelling older women concluded that urgency urinary incontinence (UUI) was associated with significantly increased average duration of SB bouts. The importance of objective measurement of SB was highlighted and it was suggested that decreasing time in prolonged sitting may be a target intervention to reduce UUI. ${ }^{27}$ Researchers conclude that there is a lack of complementary studies of higher quality on the association between SB and UI. ${ }^{28-32}$

Frailty is one of the most important concerns regarding our ageing population as it is a leading contributor to functional decline and early mortality in older adults. ${ }^{5-7}$ Evidence grows that this state is linked to several relevant health outcomes, similarly prevalent in all countries. The last consensus defined frailty as 'a clinical state in which there is an increase in an individual's vulnerability for developing an increased dependency and/or mortality when exposed to a stressor, ${ }^{8}$

Functional decline is one of the main health-related issues that affect older adults because it limits their autonomy and leads to dependency. ${ }^{33}$ In older adults, functional capacity can be defined as the ability to carry out basic activities of daily living (BADL) ${ }^{10}$ The association between functional decline and UI could be bidirectional, which can lead to a cycle where continence reduction results in functional decline, and functional decline leads to further decrease in continence. ${ }^{13} 17$

Falls, though preventable, are common among older adults, and the resulting injuries can threaten their health, independence and everyday routines. Ageing is one of the main risk factors for falls, for this reason, older adults have a high risk of injuries, increased dependence, disabilities and institutionalisation. All these outcomes are also risk factors for frailty. ${ }^{18}{ }^{19}$ Several studies have shown that the transition from in-home to institutional care is related to substantially higher mortality rates, as well as reduced physical and cognitive function. ${ }^{2028}$ It is well known that hospital admission can affect the process of usual ageing due to adverse health outcomes after hospitalisation, especially in terms of functional decline, ${ }^{34}$ mortality, ${ }^{20}$ frailty $^{22}$ and cognitive impairment. ${ }^{23}$

Therefore, the aim of this study is to determine the prevalence of UI and its associated factors, specifically the association between UI types and SB patterns in older people living in NHs in Osona, a region of Catalonia, Spain. Also, stage I of this project aims to analyse the current status of health-related outcomes, based on the biopsychosocial model of health, and to describe the current interventions to reduce SB and increase PA, and the control measures to manage UI by the NHs of Osona. In addition to this, it aims to understand the experience of having UI among residents and the experience of providing healthcare to these individuals among health professionals, using descriptive phenomenology.

On the other hand, the SARS-CoV-2, called COVID19 , has emerged as a worldwide pandemic. ${ }^{35}$ This virus has been shown to be particularly deadly for older adults and those with certain underlying medical conditions. ${ }^{36-39}$ In relation to deaths from COVID-19 in Spain, $87 \%$ of the reported deaths were 70 years or older and $95 \%$ presented comorbidity. ${ }^{40}$ The population living in NHs, generally with older age and multiple comorbidities, are the most vulnerable to COVID-19. ${ }^{41}$ In Catalonian NHs from 28418 suspected cases, 11560 confirmed positive cases and 3055 deaths were reported until May $2020 .{ }^{42}{ }^{43}$ Due to the vulnerability of NHs themselves to outbreaks of respiratory diseases ${ }^{45}$ and the frailty of $\mathrm{NH}$ populations, there is a need to analyse the impact of COVID-19 on NH residents in terms of mortality, hospitalisation, as well as other health, social and cognitiverelated variables. 
Stage II aims to follow-up the included cohort of stage I and analyse the incidence and predictive factors for functional decline, frailty, continence decline, falls, hospitalisations and mortality among older people living in NHs for a 2-year period. The cohort first assessed before the first diagnosis of COVID-19 in NHs will be followed up to identify the potential risk and protective factors for mortality due to COVID-19 and the impact of this disease on functioning and hospitalisations.

\section{METHODS AND ANALYSIS \\ Study design}

The present study follows the STROBE (STrengthening the Reporting of OBservational studies in Epidemiology) guidelines and consists of two stages ${ }^{46}$ :

- Stage I. Observational cross-sectional study on the prevalence of UI (and its types) and SB patterns and the possible association between both issues in the older population living in NHs.

- Stage II. Observational 2-year longitudinal (cohort) study on functional and continence status, falls, hospitalisations and mortality (including COVID-19 data) among NH residents.

\section{Stage I: prevalence of $\mathrm{UI}$ and its associated factors among $\mathrm{NH}$ residents in Osona (Barcelona, Spain) \\ Design}

Cross-sectional study with mixed methodology. The starting month was September 2019, main data collection was conducted between January and March 2020 and, after data analysis, the study is planned to be finalised in May 2021.

\section{Setting and location}

The present study was conducted in NHs of Osona. According to the Catalonia Government, there are 19 registered NHs: 14 private NHs with state-subsidised places and 5 totally private NHs. The first contact with the NHs was done by email and phone call to explain the project, resolve any queries and send them the participation documents for the study if they are interested in taking part.

\section{Patient and public involvement}

There was no patient or public involvement in the design and conduct of stage I.

\section{Sample size}

The calculation of the study sample was based on the preliminary data from the pilot study. Calculating the sample from the difference between variables (presence of IU or not and the mean of the total time in hours of SB), an absolute precision of the $5 \%$ and a significance level of the $5 \%$, the sample to estimate the association between IU and SB was 120 subjects. Considering a $30 \%$ possible non-response rate, the final sample corresponds to 145 subjects. A simple random sampling was undertaken. The exclusion criteria will be given in a flow chart. ${ }^{47}$

\section{Eligibility criteria}

All NH residents (male or female) aged 65 years or older who lived in the institution permanently, with or without cognitive impairment, were included in the quantitative part of the study. Exclusion criteria were subjects in a coma or palliative care (prognosis of short life), hospitalised and those who refused to participate in the study. For the qualitative part of the study, inclusion criteria for older people were as follows: (1) voluntary participation in the study, (2) diagnosed with UI for at least 6 months and (3) able to express themselves verbally. Inclusion criteria for $\mathrm{NH}$ professionals were as follows: (1) voluntary participation in the study and (2) caring older people with UI for at least 6 months.

\section{Study procedures}

In the beginning of the project (October-November 2019), the research team was trained, received standardised operating procedures and was calibrated to ensure the reliability of the data regarding anthropometry, handgrip test and Short Physical Performance Battery (SPPB) with its corresponding calculation of the interclass correlation coefficient. After the calibration, a pilot study was conducted with a minimum of 20 participants in January 2020, with the aim to check if the evaluations and tests were reliable. Before starting data collection, every NH director accepted the participation in the project with a formal consent. After that, the list of residents was obtained, and the individuals were selected according to inclusion/exclusion criteria. Then, the residents or their legal guardians were informed about the project and those who accepted to participate signed the informed consent. The assessment procedure started with the placement of the activPAL3 activity monitor (PAL Technologies, Glasgow, UK), a reliable and valid device considered as a gold standard to record and analyse the $\mathrm{SB}^{48-50}$

The device was worn on the anterior medial part of the right thigh, sealed with a flexible nitrile cover and adhered to the skin with a hypoallergenic adhesive dressing. The device captured data continuously during both awake and sleeping time, for 7 consecutive days. Sociodemographic information was obtained from the NH registers. Information on the continence status and other conditions were checked with the residents' caregivers. Cognitive status was assessed in all individuals and a more extended questionnaire on quality of life, incontinence, lower urinary tract symptoms, depressive and anxiety symptoms, social network and loneliness was applied to residents with cognitive capacity. ${ }^{51}$ The approximate time of application of the physical tests and the questionnaire to the participant was $30-45 \mathrm{~min}$. In case of fatigue, the participant was offered the possibility of interrupting or stopping the assessment whenever he/she wished.

\section{Data collection}

Section H of Minimum Data Set (MDS) V.3. $0^{52}$ was used to assess the presence of UI and other bladder and bowel conditions. When a resident had preserved cognitive capacity to answer questionnaires, the continence status was checked with the International Consultation 
on Incontinence Questionnaire Urinary IncontinenceShort Form (ICIQ UI-SF), validated to Spanish. ${ }^{53}$ According to the MDS and the ICIQ UI-SF, the type of UI was determined: stress, urgency, mixed and functional. The number of absorbents (pads/diapers) used daily was also considered. In addition, information on lower urinary tract symptoms was collected using the International Prostate Symptoms Score (IPSS) ${ }^{54}$ To evaluate SB, the variables of steps, duration in minutes of SB periods, total time in SB, SB bouts, total time in standing position and walking in hours, and transitions from sitting to standing were taken with the activPAL3 activity monitor (PAL Technologies, Glasgow, UK) for 7 consecutive days. The device placement was on the anterior and middle of the right thigh, or on the unaffected leg thigh in cases of stroke.

Sociodemographic variables such as age, gender, date of birth, date of institutionalisation, number and type of deliveries (vaginal or caesarean), level of education, marital status, chronic conditions (high blood pressure, diabetes, cancer, lung disease, stroke, dementia, Parkinson's, osteoporosis, kidney failure, dyslipidaemia, cardiac disease and mental illness), history/current tobacco use and alcohol consumption urinary tract infection in the last 30 days, bone fracture in the last year, hospitalisation in the last year, medication and normal routine blood analysis from $\mathrm{NH}$ records (biochemical data for vitamin $\mathrm{D}$, albumin, pre-albumin and C-reactive protein) were recorded. Regarding health-related variables, delirium, ulcers (any type), functional ability (modified Barthel Index) ${ }^{5556}$ cognitive status (Pfeiffer Scale),${ }^{51}$ faecal incontinence (according to MDS V.3.0), lower tract urinary symptoms (through the IPSS), falls during the last year (number, places and consequences, from $\mathrm{NH}$ records), physical capacity using the Short Physical Performance Battery (SPPB) ${ }^{57}$ mobility (Rivermead Mobility Index) ${ }^{58}$ frailty (Clinical Frailty Scale) ${ }^{59}$ and quality of life using the self-reported questionnaire EUROQOL-5D (EQ$5 \mathrm{D})^{60}$ were assessed. To ensure a possible comparison with other studies on sarcopenia/frailty, the handgrip strength measured by JAMAR Plus Digital Hand dynamometer $^{61}$ and any unintended weight loss in the last year (more than $4.5 \mathrm{~kg}$ or more than $5 \%$ of previous weight in the last year) were recorded. The approximate consumption liquids (water and drinks in millilitres and types of drinks) were collected over a 24-hour period, completed by the residents themselves if their cognitive capacity was sufficiently preserved, or by health professionals of the NHs. The total number of daily use medications was registered, as well as the types of medications, according to the international Anatomical Therapeutic Chemical classification system (ATC) ${ }^{62}$ In addition, psychosocial factors were considered in all residents with sufficient cognitive capacity to answer questionnaires: number of monthly visits from friends/family, according to the caregivers, as well as the Yesavage Geriatric Depression Scale (5-GDS) ${ }^{63}$ to assess depressive symptoms, the Hospital Anxiety and Depression Scale (HADS) for anxiety, ${ }^{64}$ social networks through the Lubben Social Network Scale ${ }^{65}$ and loneliness through the 6-item De Jong-Gierveld Loneliness Scale. ${ }^{667}$

Anthropometric variables included weight $(\mathrm{kg})$, height $(\mathrm{m})$, body mass index $\left(\mathrm{kg} / \mathrm{m}^{2}\right)$, arm circumference $(\mathrm{cm})$, waist circumference $(\mathrm{cm})$, hip circumference $(\mathrm{cm})$ and calf circumference $(\mathrm{cm})$. These measurements were obtained using a Seca 213 measuring device (Seca Medizinische Messsysteme und Waagen, Hamburg, Deutschland) and a measuring tape. Measures related to body composition were reported as a percentage $(\%)$ of body fat, $\%$ of fat-free mass and $\%$ of body water, using a Tanita TBF-300 bioimpedance device (Tanita Institute, Tokyo, Japan). ${ }^{68}$ Finally, the nutritional status was evaluated by the Mini Nutritional Assessment Test (MNA), ${ }^{69}$ considered as a gold standard method for evaluating nutritional status in old people.

In the qualitative part of the study, descriptive phenomenology will be used, as it is one of the leading methodologies used in social sciences and healthcare research in order to understand the lived experiences of individuals. ${ }^{70}$ Therefore, to understand the experience of having UI among residents and to explore health professionals' experience of providing health services to residents with UI, descriptive phenomenology is planned to be considered as the methodological approach of the qualitative part. We aimed for the participants to be heterogeneous in terms of their descriptive characteristics (eg, age, gender, duration and level of incontinence among residents; gender and years of experience with residents with UI among health professionals).

During the initial plan, two semistructured interview guides will be used: one with residents and one with health professionals. The guides were created by the researchers with two general research questions in mind: (1) What is your experience of having UI and what effects does it have on everyday life? (2) How is the experience of providing healthcare to residents with UI and what are the difficulties experienced in this aspect? Individual interviews were considered as the data collection method to use with residents due to the delicate character of the experienced problem; meanwhile, with health professionals, a focus group was considered as an ideal data collection method and facilitates remembering forgotten experiences. In both interviews, the data collection process will be terminated after data saturation is reached, in other words, when no new topic arises during the interviews. ${ }^{71}$ As recommended by Sandelowski, ${ }^{72}$ the sample size must be large enough to allow the unfolding of a new and richly textured understanding of the studied phenomenon, but small enough to be able to do a deep and case-oriented analysis of the qualitative data. In the qualitative analysis of the obtained data, Colaizzi's phenomenological data analysis method will be considered. This method was largely influenced by Husserl's descriptive phenomenological approach and will allow the researchers to discover the fundamental structures of the phenomena which is being investigated. ${ }^{73}$ 
The feasibility of the qualitative dimension was adversely affected by the physical restrictions applied in NHs due to the COVID-19 pandemic as face-to-face interviews with residents and focus groups with health professionals were considered unsafe for both participant groups due to increased risk of transmission. For this reason, online video conferencing was planned to be used during the collection of the qualitative data. However, it is foreseen that conducting individual interviews via video conferencing with residents will decrease both the applicability of the interview and the quality of the data obtained due to their unfamiliarity with this virtual method and the possible auditory and/or visual limitations that they may have. Thus, it was decided to exclude the dimension of UI experiences among residents and only have individual interviews with healthcare professionals via video conferencing instead of creating online focus groups, which will be relatively challenging to manage virtually.

\section{Statistical analysis}

First, descriptive analysis will be undertaken indicating absolute and relative frequencies for categorical variables and mean and SD for quantitative variables. Before doing the bivariate analysis, a subanalysis of the minimum number of days with the activPAL that are necessary to have a reliable data record on SB will be performed, following the PA procedure performed by Reid et al. ${ }^{74}$ Subsequently, the bivariate analysis will be applied through the $\chi^{2}$ test (or Fisher's test) and the linear $\chi^{2}$ test in case of dichotomous or ordinal variables, as well as the Student's t-test for quantitative variables. As an association measure, the prevalence ratio will be used, with a confidence level of $95 \%$. The multivariate analysis will be undertaken through the Poisson regression with robust variance.

\section{Stage II: incidence and predictor factors of functional and continence decline, falls, hospitalisations, mortality among older people in NHs: a 2-year cohort study \\ Design}

Stage II of the OsoNaH project is a longitudinal prospective 2-year study and follows the STROBE guidelines. ${ }^{46}$ The starting month was January 2020 and, following the data analysis, the study is planned to be finalised in December 2022. Data will be collected every 6 months over 2 years focusing on functional decline, frailty, continence status, hospitalisations, mortality, diagnosis and suspected cases of COVID-19 and changes in the medication of their residents in the $\mathrm{NHs}$, already assessed at the baseline from January to March 2020. The information is provided by the NH staff and the NH records according to the COVID-19 health measures, by phone call or email avoiding direct contact with the NH staff.

\section{Setting}

NHs and residents participating in stage I will be followed up over the next 2 years. Every 6 months through interviews with the professionals of the institutions will be asked for information on functional decline, frailty, continence status, hospitalisations, mortality, diagnosis and suspected cases of COVID-19, COVID-19 containment measures within NHs and changes in the medication of their residents. Data related to falls will be collected through a continuous prospective register in every institution.

\section{Patient and public involvement}

There was no patient or public involvement in the design and conduct of stage II.

\section{Sample size}

According to a 2-year longitudinal study conducted by Jerez-Roig $e t a l^{44}$ in institutionalised older people, an initial sample of 280 people is powered to detect prognostic factors of functional decline.

\section{Eligibility criteria}

NHs residents (male or female) aged 65 years or older who live in the institution permanently will be included. Subjects in coma or palliative care (prognosis of short life) will be excluded. For the study of functional decline, residents with limitations in all basic activities of daily living will be excluded from the study. For the study of continence decline, the participants who have a urinary catheter fitted, or ostomy, as well as those with total UI defined by Section H of MDS V.3. $0^{52}$ at baseline will be excluded. For analysing the incidence of falls, those subjects who do not walk independently (with or without aids) will be excluded.

\section{Study procedures}

From the baseline of January 2020 to March 2020, every 6 months the data will be collected, until accomplishing the 2-year follow-up, in March 2022. The data are provided by the NH staff and the NHs who previously agreed to participate in the study signing the informed consent to access the records and the variables of mortality and causes, hospitalisations and causes, falls, functional capacity evaluated by means of the Barthel scale, frailty evaluated by the Clinical Frailty Scale, COVID-19 diagnostic by test (PCR or serological), suspected case of COVID-19 and modifications in the medication in the last 6 months. Due to COVID-19 restrictions, interviews are conducted by phone call or email with the NH staff every 6 months.

\section{Data collection}

Functional status will be assessed by the modified (5-point Likert scale) Barthel's Index. Continence status will be assessed using Section H of MDS V.3.0. Falls will be registered continuously taking into account the date, location and consequences of falls. Dates and causes of hospitalisations and mortality (dates and causes) will also be registered retrospectively during the 6-month assessments. For the COVID-19-related variables, the following information will be collected: date and results of diagnosis tests of COVID-19 (PCR or serological antibody test), suspected case (symptoms of cough, fever and/ 
or breathing difficulties during the previous 6 months) and room lockdown (duration in days). The levels of frailty of the resident will be assessed with the Clinical Frailty Scale. ${ }^{59}$ Finally, any new comorbidity diagnosis as well as any change in the regular medication (registered according to ATC classification ${ }^{62}$ ) in the last 6 months will be assessed.

\section{Statistical analysis}

The actuarial method will be used to analyse functional and continence decline throughout the 5-wave cohort. The Kaplan-Meier method will be used for falls, hospitalisations and deaths. Log-rank test will be applied for bivariate analysis. Those variables with $\mathrm{p}<0.25$ and variables 'age' and 'sex' will be considered susceptible for testing in the multiple model. Multivariate analysis will be performed using Cox regression. Forward selection will be used to introduce covariables in the model, first introducing those variables with higher $\mathrm{HR}$ values and observing the behaviour and adjustment of the model (stepwise forward). Risk measurements will be presented for HR, with the respective CI and $p$ values. Finally, the proportionality test will be carried out for the final model, followed by Schoenfeld residual analysis to verify validity of Cox's semiparametric model. The ROC curve will be analysed to determine the predictive ability of the created functionality decline index. The inferential statistical analysis will be performed at a $95 \%$ confidence level.

\section{ETHICS AND DISSEMINATION}

The study received the following approvals: University of Vic - Central University of Catalonia (UVic-UCC) Ethics and Research Committee (92/2019 and 109/2020), Clinical Research Ethics Committee of the Osona Foundation for health research and education (FORES) (code 2020118/PR249). On December 2019, the UVic-UCC's Ethics and Research Committee approved an amendment to the project that consisted of adding questionnaires on physical activity, loneliness, social network and number of visits to residents. Later, modifications due to COVID-19 restrictions were evaluated and approved by the same Ethics and Research Committee on November 2020 with registry number 009.

Every NH director accepted the participation in the project with a formal consent. Then, NH staff were informed about the project and the ones who accepted to participate signed the informed consent. Finally, the selected residents or their legal guardians were informed about the project and those who accepted to participate signed the informed consent. Participants also had been informed that they could withdraw from the study at any time without giving any reasons.

Study results will be disseminated at conferences, meetings and through peer-reviewed journals. The researchers may also communicate the results to NHs, NH staff, residents and resident's families.

\section{Author affiliations}

${ }^{1}$ Research Group on Methodology, Methods, Models and Outcomes of Health and Social Sciences $\left(\mathrm{M}_{3} \mathrm{O}\right)$, Faculty of Health Sciences and Welfare, Centre for Health and Social Care Research (CESS), University of Vic-Central University of Catalonia (UVic-UCC), Vic, Barcelona, Spain

${ }^{2}$ Research group on Tissue Repair and Regeneration Laboratory (TR2Lab), Faculty of Health Sciences and Welfare, Centre for Health and Social Care Research (CESS), University of Vic-Central University of Catalonia (UVic-UCC), Vic, Barcelona, Spain ${ }^{3}$ Fundació Salut i Envelliment (Foundation on Health and Ageing), Autonomous University of Barcelona, Barcelona, Spain

${ }^{4}$ Research group on Mental Health and Social Innovation (SAMIS), Faculty of Health Sciences and Welfare, Centre for Health and Social Care Research (CESS), University of Vic-Central University of Catalonia (UVic-UCC), Vic, Barcelona, Spain ${ }^{5}$ Department of Collective Health, Federal University of Rio Grande do Norte, Natal, Brazil

${ }^{6}$ Research Centre for Health (ReaCH), School of Health and Life Sciences, Glasgow Caledonian University, Glasgow, UK

${ }^{7}$ Faculty of Psychology, Education and Sport Sciences Blanquerna, Ramon Llull University, Barcelona, Spain

${ }^{8}$ Faculty of Health Sciences Blanquerna, Ramon Llull University, Barcelona, Spain

Twitter Pau Farrés-Godayol @PauFarrs, Javier Jerez-Roig @javierjerezroig, Meltem Yildirim @mltmyldrm9 and Dawn A Skelton @LaterLifeTrain \& @GCUResearch

Contributors PF-G, JJ-R, MG-G and EM-M were involved in designing of the study and the writing of the manuscript. AES, MM, PM-M, SR-C, SR-F and MY were involved in the acquisition of data. DB participated in the design and the sample size calculation. EG-R, LC-P, MR-M, MT-M, JN-M, DB, JB, DS and the rest of authors reviewed drafts of the paper and approved the final draft.

Funding This work was supported by the Hestia foundation (grant number BI-CHAISS-2019/003) and the Col-legi de Fisioterapeutes de Catalunya (grant number R03/19).

Competing interests None declared.

Patient and public involvement Patients and/or the public were not involved in the design, or conduct, or reporting or dissemination plans of this research.

Patient consent for publication Not required.

Provenance and peer review Not commissioned; externally peer reviewed.

Open access This is an open access article distributed in accordance with the Creative Commons Attribution Non Commercial (CC BY-NC 4.0) license, which permits others to distribute, remix, adapt, build upon this work non-commercially, and license their derivative works on different terms, provided the original work is properly cited, appropriate credit is given, any changes made indicated, and the use is non-commercial. See: http://creativecommons.org/licenses/by-nc/4.0/.

\section{ORCID iDs}

Pau Farrés-Godayol http://orcid.org/0000-0002-6335-9825

Javier Jerez-Roig http://orcid.org/0000-0002-1968-4452

Eduard Minobes-Molina http://orcid.org/0000-0002-0457-2503

Meltem Yildirim http://orcid.org/0000-0002-9699-3099

Ester Goutan-Roura http://orcid.org/0000-0003-0990-9387

Laura Coll-Planas http://orcid.org/0000-0001-5204-8717

Anna Escribà-Salvans http://orcid.org/0000-0003-3419-7174

Miriam Molas-Tuneu http://orcid.org/0000-0002-6743-2161

Sandra Rierola-Fochs http://orcid.org/0000-0003-3677-975X

Montse Romero-Mas http://orcid.org/0000-0002-8079-1433

Miriam Torres-Moreno http://orcid.org/0000-0002-7808-043X

Jordi Naudó-Molist http://orcid.org/0000-0003-3731-2350

Dyego Leandro Bezerra de Souza http://orcid.org/0000-0001-8426-3120

Joanne Booth http://orcid.org/0000-0002-7870-6391

Dawn A Skelton http://orcid.org/0000-0001-6223-9840

Maria Giné-Garriga http://orcid.org/0000-0003-4449-3524

\section{REFERENCES}

1 People in the EU - statistics on an ageing society. Statistics explained, 2020. Available: https://ec.europa.eu/eurostat/statisticsexplained/index.php?title=People_in_the_EU_-_statistics_on_an_ ageing_society 
2 Harwood RH. Do we still need care homes? Age Ageing 2004:33:529-30.

3 Gordon AL, Franklin M, Bradshaw L, et al. Health status of UK care home residents: a cohort study. Age Ageing 2014:43:97-103.

4 Jerez-Roig J, de Medeiros JF, do Nascimento Moreira Fidélis K, et al Activity limitations in Brazilian institutionalized older adults. $J$ Geriatr Phys Ther 2017:40:214-22.

5 Vermeiren S, Vella-Azzopardi R, Beckwée D, et al. Frailty and the prediction of negative health outcomes: a meta-analysis. J Am Med Dir Assoc 2016;17:1163.e1-1163.e17.

6 Hoogendijk EO, Muntinga ME, van Leeuwen KM, et al. Self-perceived Met and unmet care needs of frail older adults in primary care. Arch Gerontol Geriatr 2014;58:37-42.

7 Dent E, Morley JE, Cruz-Jentoft AJ, et al. Physical frailty: ICFSR international clinical practice guidelines for identification and management. J Nutr Health Aging 2019;23:771-87.

8 Morley JE, Vellas B, van Kan GA, Abellan van Kan G, et al. Frailty consensus: a call to action. J Am Med Dir Assoc 2013;14:392-7.

9 Verbrugge LM, Jette AM. The disablement process. Soc Sci Med 1994;38:1-14.

10 Macêdo AMLL CEAN, Alvarenga MRM, Faccenda O, et al. Avaliação funcional de idosos CoM déficit cognitivo. ACTA Paul Enferm 2012;25:358-63.

11 Jerez-Roig J, Santos MM, Souza DLB, et al. Prevalence of urinary incontinence and associated factors in nursing home residents. Neurourol Urodyn 2016;35:102-7.

12 Jerez-Roig J, Moreira FSM, da Câmara SMA, et al. Predicting continence decline in institutionalized older people: a longitudinal analysis. Neurourol Urodyn 2019;38:958-67.

13 Agulló EM, Cerdá JLR, Pérez LG, et al. Prevalencia de incontinencia urinaria Y vejiga hiperactiva en La población española: Resultados del Estudio EPICC. Actas Urológicas Españolas 2009;33:159-66.

14 Sackley CM, Levin S, Cardoso K, et al. Observations of activity levels and social interaction in a residential care setting. Int $J$ Ther Rehabil 2006;13:370-3.

15 Marmeleira J, Ferreira S, Raimundo A. Physical activity and physical fitness of nursing home residents with cognitive impairment: a pilot study. Exp Gerontol 2017;100:63-9.

16 Boyington JEA, Howard DL, Carter-Edwards L, et al. Differences in resident characteristics and prevalence of urinary incontinence in nursing homes in the southeastern United States. Nurs Res 2007;56:97-107.

17 Coll-Planas L, Denkinger MD, Nikolaus T. Relationship of urinary incontinence and late-life disability: implications for clinical work and research in geriatrics. Z Gerontol Geriatr 2008;41:283-90.

18 Pellicer B, Juárez-Vela R, Sevilla D, et al. Prevalence and profile of the elderly home care valid suffering in a private residence falls. Rev Enferm 2013;36:8-16.

19 Siqueira FV, Facchini LA, da SDS, et al. Prevalence of falls in elderly in Brazil: a. Cad Saude Publica 2011;27:1819-26.

20 Ponzetto M, Maero B, Maina P, et al. Risk factors for early and late mortality in hospitalized older patients: the continuing importance of functional status. J Gerontol A Biol Sci Med Sci 2003;58:M1049-54.

21 Walter LC, Brand RJ, Counsell SR, et al. Development and validation of a prognostic index for 1-year mortality in older adults after hospitalization. JAMA 2001;285:2987.

22 Feng L, Nyunt MSZ, Gao Q. Physical frailty, cognitive impairment, and the risk of neurocognitive disorder in the Singapore longitudinal ageing studies. Journals Gerontol - Ser A Biol Sci Med Sci 2017;72:369-75.

23 Feng L, Zin Nyunt MS, Gao Q, et al. Cognitive frailty and adverse health outcomes: findings from the Singapore longitudinal ageing studies (SLAS). J Am Med Dir Assoc 2017;18:252-8.

24 World Health Organization. Global Recomendations on physical activity for health. Geneva: World Health Organization, 2010: 58.

25 van der Ploeg HP, Venugopal K, Chau JY, et al. Non-occupational sedentary behaviors: population changes in the Netherlands, 19752005. Am J Prev Med 2013:44:382-7.

26 Bellettiere J, Carlson JA, Rosenberg D, et al. Gender and age differences in hourly and daily patterns of sedentary time in older adults living in retirement communities. PLoS One 2015;10:e0136161.

27 Jerez-Roig J, Booth J, Skelton DA, et al. Is urinary incontinence associated with sedentary behaviour in older women? analysis of data from the National health and nutrition examination survey. PLoS One 2020;15:e0227195

28 Aneshensel CS, Pearlin LI, Schuler RH. Mortality among people with dementia. J Gerontol Soc Sci 2000;55:152-62.

29 Lee AH, Hirayama F. Physical activity and urinary incontinence in older adults: a community-based study. Curr Aging Sci 2012:5:35-40.
30 Leirós-Rodríguez R, Romo-Pérez V, García-Soidán JL. Prevalencia de la incontinencia urinaria Y SU relación Con El sedentarismo en España. Actas Urol Esp 2017;41:624-30.

31 Stenzelius K, Molander U, Odeberg J, et al. The effect of conservative treatment of urinary incontinence among older and frail older people: a systematic review. Age Ageing 2015;44:736-44.

32 Steenstrup B, Le Rumeur E, Moreau S, et al. [Sedentary lifestyle and urinary incontinence in women: A literature review]. Prog Urol 2018;28:973-9.

33 Suskind AM, Cawthon PM, Nakagawa S, et al. Urinary incontinence in older women: the role of body composition and muscle strength: from the health, aging, and body composition study. J Am Geriatr Soc 2017;65:42-50.

34 Jerez-Roig J, de Brito Macedo Ferreira LM, Torres de Araújo JR, et al. Functional decline in nursing home residents: a prognostic study. PLoS One 2017;12:e0177353.

35 WHO Director-General's opening remarks at the media briefing on COVID-19 - 11 March 2020, 2020. Available: https://www.who.int/ director-general/speeches/detail/who-director-general-s-openingremarks-at-the-media-briefing-on-covid-19---11-march-2020 [Accessed 12 Gen 2021].

36 Nikolich-Zugich J, Knox KS, Rios CT. SARS-CoV-2 and COVID-19 in older adults: what we may expect regarding pathogenesis, immune responses, and outcomes. GeroScience 2020;19:505-14.

37 Shahid Z, Kalayanamitra R, McClafferty B, et al. COVID-19 and older adults: what we know. J Am Geriatr Soc 2020;68:926-9.

38 Fu L, Wang B, Yuan T, et al. Clinical characteristics of coronavirus disease 2019 (COVID-19) in China: a systematic review and metaanalysis. J Infect 2020;80:656-65

39 Onder G, Rezza G, Brusaferro S. Case-fatality rate and characteristics of patients dying in relation to COVID-19 in Italy. JAMA 2020;323:2019-20.

40 Instituto de Salud Carlos III y Centro Nacional de Epidemiología. Informe sobre La situación de COVID-19 en España Contenido, 2020. Available: https://www.isciii.es/QueHacemos/Servicios/ VigilanciaSaludPublicaRENAVE/EnfermedadesTransmisibles/ Documents/INFORMES/Informes\%20COVID-19/Informe\%20n\% C2\%BA\%2029.\%20Situaci\%C3\%B3n\%20de\%20COVID-19\% 20en\%20Espa\%C3\%B1a\%20a\%2007\%20de\%20mayo\%20de\% 202020.pdf

41 D'Adamo H, Yoshikawa T, Ouslander JG, et al. In geriatrics and long-term care: the ABCDs of COVID-19. J Am Geriatr Soc 2019;2020:1-6.

42 Dades actualitzades SARS-CoV-2. Agència de qualitat I avaluació sanit ries de Catalunya (AQuAS), 2020. Available: http://aquas. gencat.cat/ca/actualitat/ultimes-dades-coronavirus/

43 Mapa de mortalitat per comarques. Agència de qualitat I avaluació sanit ries de Catalunya (AQuAS), 2020. Available: http://aquas. gencat.cat/ca/actualitat/ultimes-dades-coronavirus/mapa-mortalitatcomarques/

44 Lansbury LE, Brown CS, Nguyen-Van-Tam JS. Influenza in long-term care facilities. Influenza Other Respi Viruses 2017;11:356-66.

45 Hand J, Rose EB, Salinas A, et al. Severe respiratory illness outbreak associated with human coronavirus NL63 in a long-term care facility. Emerg Infect Dis 2018;24:1964-6.

46 von Elm E, Altman DG, Egger M, et al. The strengthening the reporting of observational studies in epidemiology (STROBE) statement: guidelines for reporting observational studies. J Clin Epidemiol 2008:61:344-9.

47 Lwanga SK, Lemeshow S, Organization WH. Sample size determination in health studies: a practical manual/S. K. Lwanga and S. Lemeshow. Geneva: World Health Organization, 1991. https:// apps.who.int/iris/handle/10665/40062

48 Grant PM, Ryan CG, Tigbe WW, et al. The validation of a novel activity monitor in the measurement of posture and motion during everyday activities. Br J Sports Med 2006;40:992-7.

49 Kozey-Keadle S, Libertine A, Lyden K, et al. Validation of wearable monitors for assessing sedentary behavior. Med Sci Sports Exerc 2011;43:1561-7.

50 Sellers C, Dall P, Grant M, et al. Validity and reliability of the activPAL3 for measuring posture and stepping in adults and young people. Gait Posture 2016;43:42-7.

51 Martínez de la Iglesia J, Dueñas Herrero R, Onís Vilches MC, et al. [Spanish language adaptation and validation of the Pfeiffer's questionnaire (SPMSQ) to detect cognitive deterioration in people over 65 years of age]. Med Clin 2001;117:129-34.

52 Klusch L. The MDS 3.0 and its impact on bladder and bowel care. Provider 2012;38:33.

53 Espuña Pons M, Rebollo Alvarez P, Puig Clota M. [Validation of the Spanish version of the International Consultation on Incontinence 
Questionnaire-Short Form. A questionnaire for assessing the urinary incontinence]. Med Clin 2004;122:288-92.

54 Badía X, García-Losa M, Dal-Ré R. Ten-language translation and harmonization of the International prostate symptom score: developing a methodology for multinational clinical trials. Eur Urol 1997;31:129-40.

55 Shah S, Vanclay F, Cooper B. Improving the sensitivity of the Barthel index for stroke rehabilitation. J Clin Epidemiol 1989;42:703-9.

56 Baztán JJ. Índice de Barthel : Instrumento válido para la valoración funcional de pacientes con enfermedad cerebrovascular 2016.

57 Guralnik JM, Simonsick EM, Ferrucci L, et al. A short physical performance battery assessing lower extremity function: association with self-reported disability and prediction of mortality and nursing home admission energetic cost of walking in older adults view project IOM Committee on cognitive Agl. Artic J Gerontol 1994;49:85-94.

58 Collen FM, Wade DT, Robb GF, et al. The Rivermead mobility index: a further development of the Rivermead motor assessment. Int Disabil Stud 1991;13:50-4.

59 Rockwood K, Song X, MacKnight C, et al. A global clinical measure of fitness and frailty in elderly people. CMAJ 2005;173:489-95.

60 Janssen MF, Pickard AS, Golicki D, et al. Measurement properties of the EQ-5D-5L compared to the EQ-5D-3L across eight patient groups: a multi-country study. Qual Life Res 2013;22:1717-27.

61 Sipers WMWH, Verdijk LB, Sipers SJE, et al. The Martin Vigorimeter Represents a Reliable and More Practical Tool Than the Jamar Dynamometer to Assess Handgrip Strength in the Geriatric Patient. $J$ Am Med Dir Assoc 2016;17:466.e1-466.e7.

62 WHO Collaborating Centre for Drug Statistics Methodology. Guidelines for ATC classification and DDD assignment 2013. 16th ed. Oslo: WHO Collaborating Centre for Drug Statistics Methodology, 2012: 284

63 Martínez de la Iglesia J, Onís Vilches MC, Dueñas Herrero R, et al. Versión española del cuestionario de Yesavage abreviado (GDS) para
El despistaje de depresión en mayores de 65 años: adaptación Y validación. Medifam 2002;12:1206-12.

64 Herrero MJ, Blanch J, Peri JM, et al. A validation study of the hospital anxiety and depression scale (HADS) in a Spanish population. Gen Hosp Psychiatry 2003;25:277-83.

65 Lubben J, Blozik E, Gillmann G, et al. Performance of an abbreviated version of the Lubben social network scale among three European community-dwelling older adult populations. Gerontologist 2006;46:503-13.

66 Buz J, Adánez GP. Análisis de la escala de soledad de de jong gierveld mediante El modelo de Rasch. Univ Psychol 2013;12:971-81.

67 Gierveld JDJ. Van Tilburg T. a 6-item scale for overall, emotional, and social loneliness: confirmatory tests on survey data. Res Aging 2006;28:582-98.

68 Cridlig J, Alquist M, Kessler M, et al. Formulation of a dry weight bioimpedance index in hemodialysis patients. Int $J$ Artif Organs 2011;34:1075-84.

69 Guigoz Y, Vellas BJ, Garry PJ. Mini nutritional assessment: a practical tool for grading the nutritional state of elderly patients. Facts Reserch Gerontol 1994;4:15-59.

70 Christensen M, Welch A, Barr J. Husserlian descriptive phenomenology: a review of intentionality, reduction and the natural attitude. J Nurs Educ Pract 2017;7:113.

71 Holloway IWS. Qualitative research in nursing and healthcare. 3rd ed. United Kingdom: Wiley-Blackwell Publishing, 2010: 146-7.

72 Sandelowski M. Sample size in qualitative research. Res Nurs Health 1995;18:179-83.

73 Wirihana L, Welch A, Williamson M, et al. Using Colaizzi's method of data analysis to explore the experiences of nurse academics teaching on satellite campuses. Nurse Res 2018;25:30-4

74 Reid N, Eakin E, Henwood T, et al. Objectively measured activity patterns among adults in residential aged care. Int J Environ Res Public Health 2013;10:6783-98. 